\title{
The Labor Force Participation Rate: An Examination Of The Determinants Of Its Recent Precipitous Decline
}

Patrick J. Litzinger, Robert Morris University, USA John H. Dunn, Jr., Robert Morris University, USA

\begin{abstract}
The Labor Force Participation Rate (LFPR) is defined as those Americans in the labor force, i.e. above the age of sixteen, below retirement age, who are either actively employed or actively seeking employment. From 1950 until 1998 it rose from 59.2\% to 67.2\%. Given the near doubling of the U.S. population, its impact on our economy was enormous. However, since 1998 the LFPR has declined steadily to 63.3\%. Parallel to this decline, we have seen a polarization of both wealth and income in the U.S. Many economists have examined both trends - the decline of LFPR and inequality - and have put forth a variety of determinants. These include technology and globalization - a decline or "hollowing out" of the middle class, if you will. Also included are the demographics of an ageing society, and the increased racial and gender participation, but also a workforce that has become only marginally prepared by today's educational institutions. Another class of determinants is the welfare "safety net" at both the Federal and state levels, including extended unemployment benefits, disability payments and other subsidies. The authors examine each class of determinants, including whether their aspects are cyclical, structural or even part of an ominous trend for our economy.
\end{abstract}

Keywords: Labor Force Participation Rate; Hollowing Out; Unemployment Rates; Unemployment Benefits; Disability Rolls

\section{INTRODUCTION}

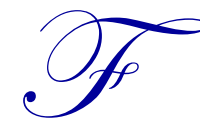

rom 1950 until 1998 the Labor Force Participation Rate (LFPR) in the United States rose from 59.2\% to $67.2 \%$. The LFPR is defined as those in the labor force, above the age of sixteen, below retirement age, who are either actively employed or actively seeking employment. That change reflects a strong and steady growth trend in labor force participation in the United States. That growth coincides with a number of structural changes in the U. S. economy and society. Since 1998, however, the LFPR has declined steadily. In addition, there appears to be a polarization of wealth and income in the United States accompanying the decline in LFPR.

There are a number of reasons advanced for the decline in the rate since 1998. Those reasons include technological change and globalization, an ageing society, a workforce that is only marginally prepared for today's jobs, and the welfare "safety net" set up at both the Federal and state levels in the United States. Each of these proposed reasons for the decline need to be examined in order to even address some understanding of the change. Policy proposals cannot be considered until some minimal understanding of the situation is achieved.

One concern for the situation facing the U. S. economy today is that the decline of the LFPR since 1998 is primarily the result of losses of individuals in the labor force who would traditionally be called members of the middle class. This concern focuses on the decline or "hollowing out" of middle class workers. Of particular concern in this view is the possible reversal of a long-standing feature of growth, or improvement, in social wellbeing in the country. As Thomas Edsall (2012) describes the concern: 
"The issue of the disappearing middle is not new, but credible economists have added a more threatening twist to the argument: the possibility that a well-functioning, efficient modern market economy, driven by exponential growth in the rate of technological innovation, can simultaneously produce economic growth and eliminate millions of middle-class jobs." makers.

It is a concern which has significant meaning to individual members of the labor force as well as policy

The aging of the "baby boom" generation in the United States is now causing large numbers of people at traditional retirement age. This phenomenon will continue for a number of years. It would appear though that the nature of the 2008-2009 recession is exacerbating this problem. Larger numbers of the "baby boom" generation may be "retiring" than would be the case had this particularly severe global recession not occurred. Individuals in the 50's and early 60's age brackets may be continuing what began as unemployment during the recession. Faced with not finding employment comparable to that which they had prior to the recession, more people in those age brackets may be moving into "retirement" without ever returning to work.

While labor force participants in the senior groups of the traditional workforce may be starting earlier than anticipated retirement, there is arguably a problem with sufficiently prepared numbers of individuals in the younger age groups of the labor force. Proponents of this concern ask the question: "Are younger members of the labor force adequately trained for the jobs in the technological society of this century?" That question suggests a number of issues. There is the concern as to whether, or not, educational institutions are offering appropriate courses of job preparations for younger people. There is the concern of how the economy and society are to match individuals with jobs given a different workforce and new technological requirements for those workers.

Another concern associated with the recession of 2008-2009 and the slow recovery in employment after the recession is the welfare "safety net" found at the Federal and state government levels in the United States. Those who voice this concern wonder if the relatively recent decline in the U. S. LFPR is the result of choices made by people left unemployed for cyclical or structural reasons. The "safety net" is designed to support those who cannot work for any of a number of reasons. Programs designed to help workers through periods of temporary unemployment, or to support limited numbers of people through situations requiring permanent exit from the labor force, may allow people to remain unemployed longer than would be the case in absence of the "safety net". Such a concern is perhaps the most difficult of the potential causes of the decline in the LFPR to evaluate.

Key to understanding the decline in the LFPR is to separate the cyclical causes from the structural. To that end, it is necessary to examine the causes of the unemployment of Great Recession determining if there are any structural forces that are operant. The analysis of several economists seems to conclude that all of the reasons for unemployment were cyclical in nature. Next, economists that have examined LFPR conclude that it appears that those same cyclical causes account for about half of the decline in the LFPR. Our objective then is to examine the possible structural causes of the decline, e.g. technological change, demographics, and welfare, and attempt to weigh those forces and see how they contribute to the trend.

\section{LABOR FORCE PARTICIPATION RATE IN THE UNITED STATES}

The Labor Force Participation Rate ("LFPR") historically has seen three phases since World War Two: "Phase one occurred from 1948 to the mid-1960s and was characterized by a roughly stable participation rate. Phase two occurred from the mid-1960s to 2000 and was characterized by steadily rising labor force participation. Phase three began at the turn of the century and is characterized by declining labor force participation. These distinctive phases in the participation rate resulted from demographic, cultural, and institutional changes (Van Zandweghe) (italics ours). The following graph from the Bureau of Labor Statistics depicts the labor force participation rate for the three phases: 


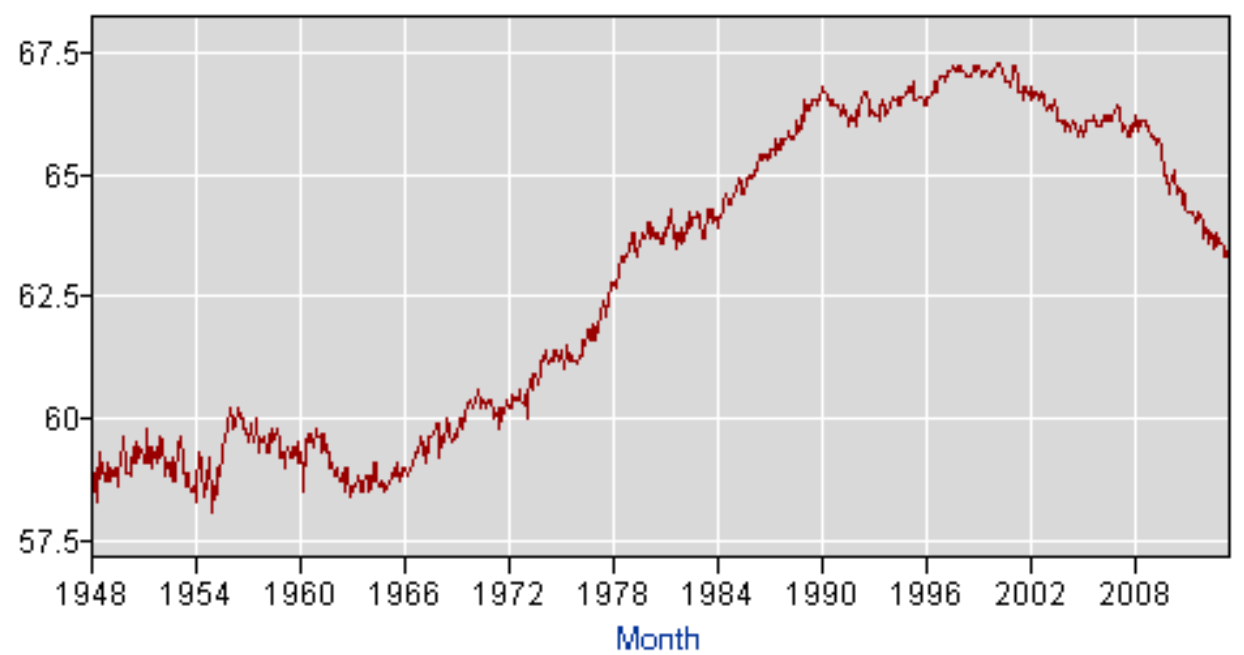

Labor Force Statistics from the Current Population Survey (1948-2013)

Series Id: LNS11300000, Seasonally Adjusted

Series title: (Seas) Labor Force Participation Rate

Labor force status: Civilian labor force participation rate

Type of data: Percent or rate

Age: 16 years and over

For phase three (2000- ), the decline in the rate is severe - from 67.3 to 63.3, and it seems to continue. In addition, as we examine the unemployment picture the denominator for determining the unemployment rate is declining with the decline in the LFPR. Thus, there is a misleading numerical decline in the stated unemployment rate. (Current Population Survey)

\section{THE GREAT RECESSION AND ITS CAUSES}

The Bureau of Labor Statistics provides monthly labor statistics for those people over 16 years of age. There are six measures of unemployment, but we focus on four:

U3: This is the official unemployment rate, which is the proportion of the civilian labor force that is unemployed but actively seeking employment.

U4: This is the official unemployment rate that is adjusted for discouraged workers. In other words, discouraged workers are treated just like other workers who are officially classified as unemployed, being included in both the ranks of the unemployed and the labor force. It is technically specified as the proportion of the civilian labor force (plus discouraged workers) that is either unemployed but actively seeking employment or discouraged workers. The addition of discouraged workers generally adds a few tenths of a percentage point to the official unemployment rate.

U5: This augments U4 by including marginally-attached workers to the unemployment rate calculation. Marginally attached workers are potential workers who have given up seeking employment for various reasons. One of these reasons is that the workers believe such effort would be futile, which places them in the discouraged worker category. Those who have other reasons for not seeking employment are placed in the broader marginally-attached workers category. The addition of marginally-attached workers adds a few more tenths of a percentage point to the official unemployment rate.

U6: This augments U5 by including part-time workers to the unemployment rate calculation. The addition of part-time workers adds a full 2-3 percentage points to the official unemployment rate. This measure of unemployment is perhaps the most comprehensive measure of labor resource unemployment available. (Portal Seven)

U3 is the generally reported measure. U6 is the interesting measure because it includes discouraged workers (those who have given up seeking employment) and part time workers. Clearly the economy affects all 
categories, but tracking the U6 allows us to see if an economic recovery, as measured by U3 is actually occurring, or simply statistically improving by people leaving the labor force, thereby reducing the denominator. Bureau of Labor Statistics measures of U3 and U6 for the period 2000-2013 are given in the following graphs:

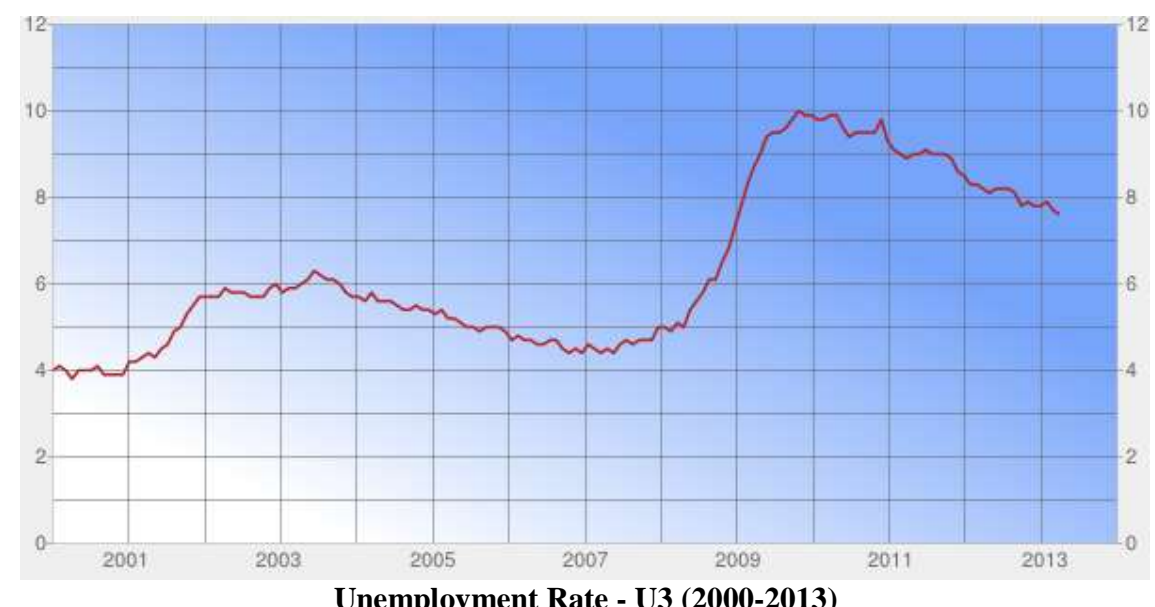

Unemployment Rate - U3 (2000-2013)

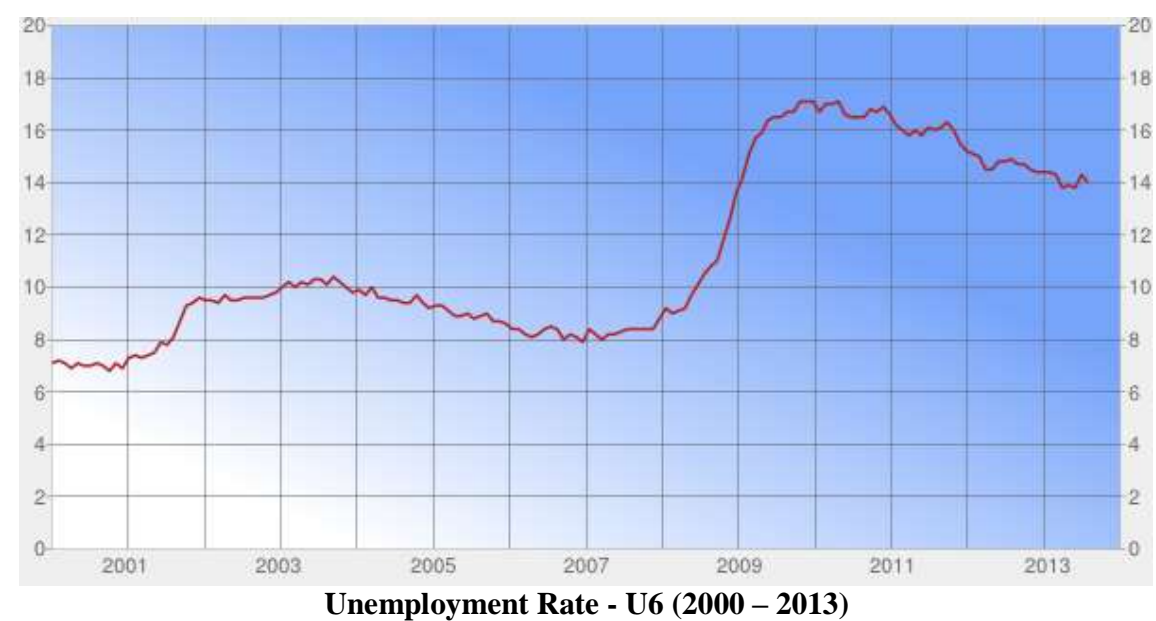

Notice that in the beginning of 2000, U3 was $4.0 \%$, and U6 was $7.1 \%$, or a differential of $3.1 \%$. At the peak of the Great Recession, U3 was $10 \%$, but U6 had risen to $17.1 \%$, or a differential of $7.1 \%$. As of June of this year, U3 had dropped to $7.6 \%$, but U6 had only declined to $14.3 \%$; again only a slight improvement in the differential to 6.7\%. Clearly, this is partly reflected in the LFPR numbers for the same time: Jan. $2000-67.2 \%$; Oct. 2009 65.1\%; Jun. $2013-63.3 \%$. But notice: instead of an improvement in the LFPR percentages, the declining trend continues.

One would assume that if a person loses his job in a recession and as the economy improves the person is rehired, the employment problem would be cyclical. On a macro basis, if the person is not rehired, then either the cyclical causes are still extant and masked by the transition from U3 to U6, or there are some significant structural conditions as well. But whether the causes are cyclical or a trend, the widening gap between U3 and U6 needs an explanation.

Probably the best study of the Great Recession, and whether its causes were cyclical or structural, was done by Edward Lazear and James Spletzer in September of 2012, The United States Labor Market: Status Quo or A New Normal?. First, they define a structural shift: "as one that is permanent (or at least long lasting)...For example, a permanent change in the amount or nature of mismatch... would be viewed as structural. The industrial composition of the economy may have changed permanently. This change might mean that the skill requirements of 
the jobs that are available today do not match the skill sets of the workers who are searching for jobs because they trained for an economic structure that has become obsolete. Monetary policy is not likely to be of much assistance in remedying these kinds of structural changes." (Lazear and Spletzer)

There are two reasons why they feel that the job losses of the Great Recession were not structural: "First, the unemployment rate was $4.4 \%$ in the spring of 2007 and rose to $10.0 \%$ by October of 2009 . Thus, in a little over two years, unemployment went up by over $5 \frac{1}{2}$ percentage points. Most structural changes do not occur so rapidly. Second, the authors see the unemployment as industry specific. Industries like manufacturing, leisure \& hospitality, construction, and wholesale \& retail have higher unemployment than vacancies in good times as well as recessions. In short these industries led the recession in unemployment, but came back as the recession ended.

The same is true for education, gender, age. Unemployment in all groups went up dramatically, and then fell similarly. There are overall trends in employment, however. The trend has been for a higher number of college graduates to be hired than those who lack a high school degree. Manufacturing has faced a long term downward trend and education and health services have seen the opposite occur. In the recession both men and women suffered unemployment, although the long term trend had been a greater female participation in the labor force. As the authors conclude: "There are trends in the labor market, some of which began many decades ago. But the trends cannot explain the sharp increase in unemployment that occurred between 2007 and 2009". For them also: "the evidence points to primarily cyclic factors." (Lazear and Spletzer)

Lazear and Speltzer leave the door open for possible structural changes as they observe the historical changes in the Beveridge Curve. The curve is a "graphical representation between the unemployment rate and the jobs opening rate." (U.S. Bureau of Labor Statistics, 2013b) The following chart shows the Beveridge curve during five separate time periods since 2000 .

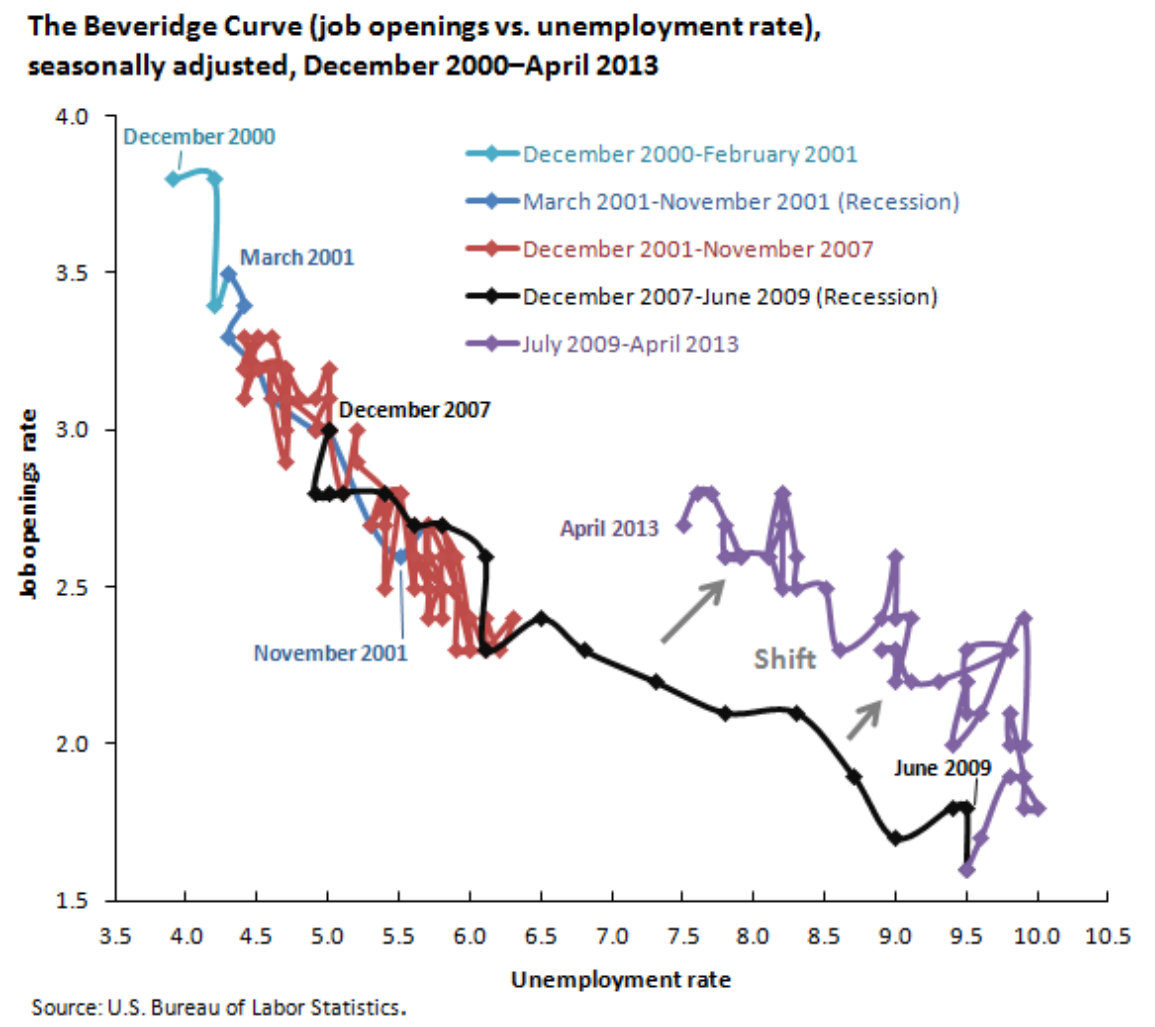

As Lazear and Spletzer point out: "Movements along the Beveridge curve are interpreted as cyclical in labor demand, whereas shifts in the Beveridge curve up and to the right are typically interpreted as structural shifts 
in unemployment, reflecting a reduced efficiency in matching workers to jobs. The apparent outward shift in the Beveridge curve and the resulting increase in unemployment may be consistent with a structural change that occurred after June 2009, but it is equally consistent with the counter-clockwise dynamics observed in previous recessions and recoveries." They add "Whether this apparent outward shift in the Beveridge curve is a permanent change cannot be known until unemployment returns to normal levels."(Lazear and Spletzer)

A publication of the U.S. Bureau of Labor Statistics, Job Openings and Labor Turnover Survey ("JOLTS") states that "The outward shift in the Beveridge curve may be due to a greater mismatch between available jobs and the unemployed in terms of skills and location, or that employers are delaying hiring due to economic uncertainty." (U. S. Bureau of Labor Statistics, 2013a) The fact that Gross Private Domestic Investment, as a percentage of the Gross Domestic Product, is now at the lowest point since 1945, may be part of this structural decline. (Bureau of Economic Analysis) If so, we will next examine that decline along with other non-cyclical forces that can account for the recent decline in Labor Force Participation.

\section{THE DECLINE IN THE LABOR FORCE PARTICIPATION RATE: ITS CAUSES}

In the first quarter of 2012, researchers at the Kansas City Federal Reserve Bank (Van Zandweghe) and the Chicago Fed (Aronson, et al.), studied the decline in the LFPR. The former states: “...the long term trend factors account for about half of the labor force participation from 2007 to 2011, with cyclical factors accounting for the other half. The latter: "The authors conclude that just under half of the post 1999 decline in the U.S. labor force participation rate ...can be explained by long running demographic patterns, such as the retirement of baby boomers." (Aronson, et al.)

Van Zandweghe uses statistical correlation to assess the impact of the business cycle: "Over a long time horizon, labor force participation has been only weakly related to the business cycle. But this long time horizon can disguise more recent movements. In fact, since 2007, the LFPR has moved more strongly with the state of the economy... From 1948 to 2011, the unemployment rate and changes in the LFPR were uncorrelated. But since the start of the recent recession in 2007, this correlation has changed to -0.13 . That is, in recent years, a higher unemployment rate has been associated with declines in labor force participation." (Van Zandweghe) His work found a steeper negative correlation at the state level. Those cyclical forces were outlined above in the section on unemployment.

The key aspects of the non-cyclical or structural decline are demographic, gender, education, and the social safety net of various welfare programs. Technology/automation/globalization has also been mentioned, but we find the literature on the subject generated more heat than light.

The composition of the population by age is affected primarily by the fact that the segment of the population, ages $25-54$ has been declining, from $58.9 \%$ in 2000, to $54.8 \%$ in 2011. In fact, Aaronson concludes that this demographic shift accounts for two thirds of this decline, and gender and education account for one third. (Aronson, et al.) Ironically, the participation rate for people 55 and older increased through the mid-nineties and has held steady since 2007. (Hartley and Zenker)

"The female share of the labor force was increasing in the 1070s, 1980s, and 1990s, and has been steady at $46.5 \%$ during the 2000s and early 2010s." (Lazear and Spletzer) The labor force participation rate of women has held steady (excluding the cyclical forces), whereas "the LFPR of men has been falling steadily for 60 years. (Hartley) This decline is attributed to increased access to Social Security benefits and the declining real wages of low-skilled workers..." (Van Zandweghe)

"The labor force share of college graduates has risen dramatically since 1992, whereas the labor force share of high school graduates has fallen steadily." (Lazear and Spletzer) This change suggests the higher level of education, the lower the unemployment. In fact the lower the age group, the higher the amount of unemployment. One would expect that since younger workers lack both years of formal education and job experience. One clear trend in post high school education may alter this: both for profit vocational schools and community colleges are moving away from the Associate degree and towards the Certificate. Both make great use of industry input, and the 
shorter training period (coupled with lower cost) allows a worker to move up in skill levels, e.g. to a welder, with commensurate increase in wages.

Many economists believe that the variety of welfare benefits have made "work less valuable". Lazear quotes University of Chicago's economist, Casey B. Mulligan that "the stimulus legislation, which lengthened the insured unemployment period, increased food stamp subsidies, and initiated programs related to health and mortgage assistance the required low income status." essentially provided little incentive to leave the unemployment rolls. This is not to attribute something untoward towards the recipients of economic assistance, but rather to the very structure of welfare programs which reduce or eliminate assistance as work is found, leaving the recipient worse off. We know from basic behavioral psychology that people will do whatever the reinforcement schedule dictates. People are rational, not malevolent.

The best empirical analysis was written by Gary Alexander, the former Secretary of Public Welfare of the Commonwealth of Pennsylvania. He writes: “ $\ldots$ a welfare recipient with two children earning a gross income of $\$ 29,000$ would receive the sum of $\$ 57,327$ in net income and welfare-assistance benefits, if you count the value of the housing -choice voucher, food stamps, daycare subsidies, and medical assistance. The same household would have to earn a gross income of $\$ 69,000$, with a net income of $\$ 57,045$ to enjoy a comparable standard of living. In other words, if the welfare recipient were earning a gross income of $\$ 29,000$, the household would turn down an opportunity to earn a gross income of $\$ 30,000$ because the benefits begin to fall off, making that household financially worse off." (Alexander)

Richard Vedder of the Ohio University's Department of Economics, wrote in the Wall Street Journal, ..." the Food Stamps program's beneficiaries rose from 17.1 million in 2000, to 26.3 million in 2007, to 47.5 million in October of 2012. Pell Grants have mushroomed from 3.9 million students in 2000 to 9.7 million in 2011.” (Vedder) The issue here is not the necessity of governmental aid for education, but one that is blind to future resultant employment. Extending unemployment benefits beyond the traditional 26 weeks, at best delays looking for employment; at worst, reinforces staying at home.

Perhaps the most ominous welfare program seemingly "designed" to exclude labor force participation is the U.S. Social Security Disability Insurance Program or SSDI. David Autor's seminal paper on SDDI, demonstrates two unfortunate aspects of the program: First, the addition to the disability rolls correlates not with the declining health of America's population, but directly with unemployment statistics: "Previous research has established that workers are most likely to apply for SDDI benefits following a job loss, a fact underscored by the pronounced positive correlation between the national unemployment rate and the SDDI application rate... Between 1989 and 2009 the share of adults receiving SDDI benefits doubled from 2.3 to 4.6 percent of Americans ages 25-64." This was due to Congress' liberalization of admission criteria to include mental health. Autor concludes: "The SDDI program is growing in size and cost in substantial part because it is supporting a rising rate of dependency and a declining rate of labor force participation among working age adults." (italics ours). The second aspect is the SDDI trust fund will be exhausted between 2015 and 2018. (Autor)

In all the studies of the Decline in the LFPR, there is no mention of technology as a cause of any structural change in our economy. Erik Brynjolfsson and Andrew McAfee wrote the Race Against The Machine, subtitled "How the Digital Revolution is Accelerating Innovation, Driving Productivity, and Irreversibly Transforming Employment and the Economy". The authors make the same observations about the economy that the previous economists have made, but see the causes as largely structural in general, and caused by automation and the digital revolution in particular. They lament that "a 2010 report published by the Federal Reserve Bank of Richmond, titled 'The Rise in Long-Term Unemployment: Potential Causes and Implications,' does not contain the words computer, hardware, software, or technology in its text." (italics, theirs). Their problem is that they assume that the unemployment and the decline in labor force participation is related to technology, but give no empirical evidence to back up their postulates. They say that "The median worker is losing the race against the machine" (Brynjolfsson and McAfee), but no economists seem to share their view. The problem of Race Against The Machine is that the authors merely recount the recent economic problems and the aspects of the digital revolution, and then attribute causality, without any statistical correlations. Temporal contiguity is not causality. 
Globalization and off-shoring have cost significant job losses, but it is beyond the scope of this paper to discuss it. Companies that manufacture off shore for that host country (GE comes to mind) are probably not causing significant unemployment. Rather it is using off shore suppliers that costs jobs, a fact consonant with the various manufactures lobbying organizations. Suffice it to say that with labor being such a small percentage of the selling price of most goods (except soft goods like textiles, apparel etc.), one can make a strong case that U.S. purchasers see their savings coming from regulation avoidance and its costs than the labor costs differential. (Dunn)

For example, two economists indirectly take issue with Brynjolfsson and McAfee's "Hollowing Out" of the middle class due to technology. David Autor and David Dorn discuss the job creation in the service sector from the advances in technology, and middle level skill jobs will be created. (Autor and Dorn) Finally, Kenneth Rogoff writes: "The next generation of technological advances could also promote greater income equality by leveling the playing field in education... Surely, higher education will eventually be hit by the same kind of sweeping wave of technology that has flattened the automobile and media industries, among others. If the commoditization of education eventually extends to at least lower level college courses, the impact on income inequality could be profound." Rogoff places his faith in market forces as opposed to government intervention.

\section{CONCLUSION}

We have examined the causes of both unemployment and the decline of the Labor Force Participation Rate. One can conclude that the forces causing the decline are largely cyclical. Those factors that are of a structural nature are largely demographic, and are exacerbated by the "unintended consequences" of inadequately conceived welfare legislation. Finally if anything technology is more likely to be part of the solution than part of the problem of an underemployed.

\section{AUTHOR INFORMATION}

Professor Litzinger is a faculty member at Robert Morris University. He teaches undergraduate and graduate courses in economics and serves as Head of the Department of Economics and Legal Studies and as Interim Associate Dean for the School of Business. He was a founder and co-director of The Leonard M. Kokkila Center for Economic Education at Robert Morris University and an original organizer and co-director of a nationally recognized conference on teaching economics held annually at Robert Morris University since 1990. He regularly makes presentations at academic conferences and meetings and is the author, or coauthor, of a number of articles and book reviews in the field of economics. He holds membership in a number of professional associations and is a past president of the Pennsylvania Economic Association. He is a member of the Board of Trustees, Sewickley Savings Bank. He is a founder and current member of the Military Affairs Council of Western Pennsylvania. He is a past president of the Airport Area Development Council and of the Western Pennsylvania Coalition for Military Presence and Job Retention. He was inducted into Phi Beta Kappa and earned a Bachelor of Arts in Political Science, a Master of Arts in Economics, and a Doctor of Philosophy in Economics at the University of Pittsburgh. E-mail: litzinger@rmu.edu (Corresponding author)

Mr. Dunn is currently an Adjunct Faculty member of the Economics and Legal Studies Department of Robert Morris University. He is also President of J.H. Dunn and Company, which provides strategic and financial advisory services to middle market corporate clients. Recent assignments have included advising the shareholders on a divestiture, two corporate sales, six acquisitions, and an independent valuation of a private company. He has served on several corporate boards, including a Houston based container manufacturing company; a Pittsburgh based manufacturer of refractory products; and on the advisory boards of a manufacturer of titanium products and an early stage enterprise serving the energy industry. Prior to establishing his company, Mr. Dunn was a Managing Director of PNC Capital Markets for ten years, actively involved in the Mergers \& Acquisitions for the corporate clients of PNC Financial Services Group. Prior to PNC, Mr. Dunn spent most of his career with commercial and investment banks, including Citigroup and before that, with the CIT Group. Recently he was appointed as a member of the Pittsburgh Business Advisory Council, of the Pittsburgh Branch of the Federal Reserve Bank of Cleveland. Mr. Dunn holds an AB Degree from Princeton University and an MBA from the University of South Carolina. E-mail: dunnj@rmu.edu 


\section{REFERENCES}

1. Alexander, Gary D., Secretary of Public Welfare, Commonwealth of Pennsylvania (2013), Statement before the Senate Budget Committee, United States Senate, February 13.

2. Aronson, Daniel, Jonathan Davis and Luojia Hu (2012), "Explaining the Decline in the U.S. Labor Force Participation Rate", Chicago Fed Letter, number 296, The Federal Reserve Bank of Chicago, March.

3. Autor, David H. (2011), "The Unsustainable Rise of the Disability Rolls in the United States: Causes, Consequences and Policy Options", November 23.

4. Autor, David H. and David Dorn (2012), "The Growth of Low Skill Service Jobs and the Polarization of the U.S. Labor Market", April.

5. Brynjolfsson, Erik, and Andrew McAfee (2011), Race Against The Machine, Digital Frontier Press.

6. Bureau of Economic Analysis, "Table 1.1.10 Percentage Share of Gross Domestic Product, Since 1929".

7. Dunn, John H., Jr. (2012), "The Decline of Manufacturing In The United States And Its Impact On Income Inequality", The Journal of Applied Business Research, September/October.

8. Edsall, Thomas B. (2012), “The Hollowing Out”Campaign Stops, The New York Times, July 8, 2012.

9. Hartley, Daniel (2011), “The Labor Force: To Work or Not To Work”, Forefront, Federal Reserve Bank of Cleveland, November.

10. Hartley, Daniel and Mary Zenker (2011), "Who is Driving the Decline in the Labor Force Participation Rate?", Cleveland Federal Reserve Bank, February 7.

11. Lazear, Edward P. and James P Spletzer (2012), "The United States Labor Market: Status Quo or A New Normal?" September 13.

12. Portal Seven.com

13. U.S. Bureau of Labor Statistics (2013a), “Job Openings and Labor Turnover Survey Highlights, May 2013", July 9.

14. U.S. Bureau of Labor Statistics (2013b), "Job Openings and the Beveridge Curve, December 2000-April 2013", July 12.

15. U. S. Bureau of Labor Statistics, Current Population Survey.

16. Van Zandweghe, William (2012), "Interpreting the Recent Decline in Labor Force Participation", Economic Review, Federal Reserve Bank of Kansas City, First Quarter 2012.

17. Vedder, Richard K. (2013), "The Wages of Unemployment”, The Wall Street Journal, January 15. 


\section{NOTES}

